\title{
3 Samba de autoria Feminina
}

* Doutora em Sociologia pela Universidade de Brasília. Professora na Universidade Estadual do Sudoeste da Bahia. Membro do Grupo de Pesquisa Cultura, Memória

Desenvolvimento.

E-mail:

nrmoreira2@yahoo.com.br
Núbia Regina Moreira*

Resumo: Inscrito no campo da sociologia da cultura, o trabalho em tela procurou deslindar as redes de interdependências que se formaram em direção a composição de samba de autoria feminina na cidade do Rio de Janeiro. O desenvolvimento da cidade carioca, a consolidação do campo da música popular brasileira e a expansão de produtores da musica direcionados aos novos nichos de consumidores se constituíram como pistas que possibilitaram compreender a manifestação de sambas de autoria feminina a partir dos anos 1970

Palavras-chave: Samba carioca. Autoria feminina. Sociologia.
Abstract: Inscribed in the field of culture sociology, this screen work attempted to untangle the networks of interdependencies which were formed toward the composition of women's samba in the city of Rio de Janeiro. The development of the carioca city, the consolidation of the field of Brazilian popular music and the expansion of music producers focused on the new consumer niches have constituted themselves clues which have enabled us to understand the manifestation of sambas being made by women since the 1970 .

Keywords: Carioca samba. Women's authorship. Sociology. 
O samba urbano apresenta um novo formato a partir das criações dos sambistas do bairro Estácio de Sá que com o bloco carnavalesco "Deixa Falar" introduziram objetos de percussão como tambores graves (surdos), tambores agudos (tamboris) e tambores de fricção (cuícas). (SANDRONI, 2001).

\section{Samba carioca e o lugar da composição feminina}

A formação do campo musical no Rio de Janeiro pode ser datada desde o século XIX onde já havia um cenário da música clássica que era estimulada pelo Imperial Conservatório de Música do Rio de Janeiro, que logo se tornaria o principal destino dos músicos dos pais (CARVALHO, 2010). No entanto, a chamada música popular se desenvolverá já no final do século XIX e se prolongará por todos os séculos seguintes, sendo que é nos anos 1940 que se inicia a profissionalização do músico popular.

Ao evocar o termo música popular estamos nos referindo a uma prática cultural que resulta de cruzamentos de diferentes experiências individuais, culturais, sociais e musicais ocorridos no cenário múltiplo das cidades modernas (TROTTA, 2006). Decorrente dessa definição, classificamos samba urbano por ser uma composição que partindo das quadras improvisadas aleatoriamente após estribilhos fixos, cantadas em coro por todo o grupo (tal como no samba corrido dos baianos), acabaria ainda - por influência dos compositores do Estácio $^{1}$ ganhando forma fixa, com a primeira e segunda parte obedecendo a tema único.

Esse tipo de samba afasta-se definitivamente do partido-alto dos baianos também ao introduzir o som do tambor encarregado de fazer prevalecer o tempo forte 2/4. (TINHORÃO, 1998). Passa a ser considerado a partir dos anos 1930 o sinônimo de samba autêntico, de "raiz", ganha espaço no mundo do rádio e dos discos, inserindose numa incipiente indústria cultural estruturada no Rio de Janeiro, a partir dos anos de 1940 (NAPOLITANO 2005).

Inserido nessa lógica, o samba urbano carioca percorrerá o caminho do revestimento da civilização brasileira e das tramas e redes que se formam a partir das estruturas relacionadas à economia capitalista e pelas práticas cotidianas dos diversos grupos representados via expressões artísticas.

Dito isso, elucidamos por meio dessas tramas a formação do campo do samba escudado em Pierre Bourdieu (1996). Para ele, ao analisar que a existência do campo é reafirmada na luta pela imposição das categorias de percepção e apreciação legítimas; existência temporalizada no envelhecimento das obras, dos autores, engendradas no "combate entre aqueles que têm interesse em deter o tempo, em eternizar o estado presente; entre os dominantes que pactuam com a continuidade, a identidade, a reprodução e os dominados, os recém-chegados, que têm interesse na descontinuidade, na ruptura, na diferença na revolução" (p. 181).

Portanto, ao recorrer ao modelo bourdieusiano, nossa expectativa foi a confirmar que a história do campo possibilitou 
2 Segundo a sambista Teresa Cristina, a composição tem lugar de destaque porque é ela que faz o samba renascer e se firmar como gênero musical que é. Entrevista concedida a autora no dia $1 \mathrm{dez} .2012$. compreender as formas de organização formal de profissionalização dos sujeitos ligados a música popular; considerando que, para isso, a consolidação de mercado de produtores e consumidores de bens culturais na sociedade brasileira corrobora para sedimentação e divisões de funções das carreiras profissionais no mundo do samba.

O campo como um produtor de normatizações, manutenção e permanência dos seus membros, estabelece hierarquizações sobre as produções que aí se inscrevem. A posição que a autoria tem ocupado no mundo do samba está imbricada à continuidade do gênero, apesar das modificações que se impõem como parte do processo de sua permanência no cenário nacional brasileiro.

O sambista compositor é o que se projeta, tem visibilidade e é símbolo deste mundo e referência cultural de significativo setor da população carioca (LIMA, 2011). A composição como capital simbólico de alto valor no campo samba é o bem em torno do qual as disputas sobre o legítimo representante da enunciação do campo se fazem relevantes, expõe seus membros através das lutas internas que num movimento histórico eterniza o campo. ${ }^{2}$

As variações do gênero naquilo que concerne à teoria musical não foram pontuadas nesse trabalho devido à nossa incompetência no assunto; interessou-nos apreender as continuidades e descontinuidades que incidiram no campo possibilitando a inserção de novos especialistas na arte de compor como, preferencialmente, as mulheres. Ao compreendermos o campo como uma processualidade histórica, notamos que a sua atual situação é marcada pelas modificações de ordem conjunturais e que, articuladas às novas tramas dos agentes, montou o cenário para novos arranjos na condição do sambista no que tange a sua posição geracional, de gênero e da incorporação do saber e fazer samba.

Segundo Lucia Lippi (2000), a cultura política do Rio de Janeiro desde Império e República até os anos de 1960 é caracterizada pelo processo de miscigenação cultural operando a fusão de gêneros, ritmos e culturas, possibilitando, assim, a criação do modelo de brasilidade difundida para o resto do país. Para autora, é no Rio de Janeiro que o modo de vida industrial moderno conhece sua origem. As relações comerciais e industriais se entrelaçam e articulam novas formas de conceber tempo e espaço, que rapidamente influenciaram reformas urbanas e as relações de trabalho.

O Rio de Janeiro será o lócus onde essas mudanças bruscas rapidamente se apresentaram. Já no final do século XIX, as remodelações do centro do Rio de Janeiro já faziam notar as injunções relativas à alteração na estrutura social do Brasil. As transformações foram impulsionadas por uma corrida pela inserção 
3 Nascida em Salvador, em 1854, presumivelmente de escravos forros, isto é, libertos após conquista ou compra de alforria, Tia Ciata chegou ao Rio de Janeiro em 1876. Lá se casou com João Batista da Silva, também negro e baiano que, em Salvador, chegara para cursar dois anos de Faculdade de Medicina e, mais tarde, conseguiu emprego no gabinete do chefe de polícia da capital federal (Cf. MOURA, 1995). do país à ordem capitalista, a qual requeria um ordenamento espacial da capital federal, que "simbolizasse a integração efetiva do País na divisão internacional do trabalho" (ABREU, 2003, p. 220).

O processo de remodelação estava presente no discurso das classes dominantes e do Estado sob a forma de combate aos cortiços, que funcionavam como moradias de trabalhadores livres ou escravos de ganho. A condução do processo de desaparecimento dos cortiços e controle da zona central da cidade era feita através das denúncias da Inspetoria Geral de Higiene e de outros órgãos, que tinham como objetivos, além de controlar essa parte do espaço urbano, também diminuir o "foco potencial de agitações populares" presentes nos cortiços (ABREU, 2003, p. 212).

É a partir do final do século XIX que a palavra "samba" começa a ser registrada na cidade do Rio de Janeiro. Assim fazendo, ela começa a diluir as fronteiras que se mostravam tão nítidas até então; e assim, pouco a pouco, “o samba já não será mais só da Bahia, nem só da roça, nem só de negros" (SANDRONI, 2001, p. 90). Inicialmente considerado como dança, festa, o samba do Rio de Janeiro tem sua origem, segundo Sandroni, na casa da Tia Ciata ${ }^{3}$.

Essa famosa baiana realizava em sua casa festas que reuniam sambistas, tendo inclusive sido o local onde fora concebido "Pelo Telefone" (1916, gravado em 1917), considerado a primeira composição do gênero. Nesse período, eram os migrantes oriundos da Bahia que gostavam de se reunir em torno da dança, da bebida e dos cantos acompanhados de instrumentos como pandeiro, chocalho, mas contavam com a presença de Pixinguinha, Donga e Sinhô, assíduos frequentadores dessas festas. É a partir da publicação do samba "Pelo Telefone" que se começa a divulgar a ideia do samba como uma síntese de vários ritmos do folguedo popular e de expressões como maxixe e tango. Parte desse processo obedece à lógica do desenvolvimento estético-expressivo do chamado samba aliado ao encaminhamento da profissionalização do artista.

Concomitante à organização técnica industrial que modelava o espaço urbano nas dimensões arquitetônica e sanitária e a campanha pela escolarização em massa de caráter laica, além da efetivação das normas jurídicas convergindo em direção à orientação de corpos e condutas, estava a sistematização das expressões de lazer, que interdependentemente conformam uma nova roupagem ao samba. Já não cabia nos anos 1930, no fluxo das interações entre os grupos, a permanência de regras pautadas na comunidade rural, tradicional. Porém, o chamado samba urbano apresenta novo formato a partir das criações dos sambistas do bairro do Estácio de Sá que, com o bloco carnavalesco "Deixa Falar", introduziram objetos de 
percussão como tambores graves (surdos), tambores agudos (tamborins) e tambores de fricção (cuícas) (Cf. SANDRONI, 2001).

A Deixa Falar era uma das inúmeras agremiações carnavalescas que surgiam a cada ano nos bairros localizados na zona portuária da cidade: “A Praça Onze, nos anos 1920, funcionava como uma espécie de convergência de todo o mundo do samba durante o carnaval. Ranchos, blocos, cordões que perambulavam pela cidade, e em algum momento passavam na Praça Onze" (FENERICK, 2002, p.108). Lembrando que, essa última, era região considerada subúrbio, embora estivesse sua localização próxima à região central da capital federal.

A separação entre as zonas suburbana e central do Rio de Janeiro obedecia às transformações espaciais provenientes da política de modernização que formataria uma sociedade civilizada aos moldes capitalistas. Entenda-se que, naquele momento, o significado da lógica capitalista-industrial era aderir ao mundo do trabalho assalariado, instaurando novas modas e comportamentos e intensificando a circulação da produção (ABREU, 2003; FENERICK, 2002).

Nesse contexto, o samba já contava com aproximação entre os grupos negro-mestiços e frações da população intelectualizada. As mediações eram, então, estabelecidas num processo de aproximação e trânsito entre diferentes segmentos e domínios sociais, resultando em interações de múltiplos estilos de vida.

As expressões populares passaram a contar, nos anos 1930, com os parcos incentivos institucionais em disputa com as artes clássicas. Essas contavam com o fomento proveniente do mecenas elitizados bem situados socialmente, favorecidos pela influência política decorrente dos cargos que ocupavam. Como consequência, a distribuição das verbas estatais para as artes atendia privilegiadamente o universo erudito em prejuízo ao universo das artes populares. Em algumas ocasiões, o financiamento fomentado pelos mecenas da alta arte, se direcionava para as manifestações populares, "sobretudo no inicio da década de 1920, quando as instituições como o rádio ainda apresentavam uma atividade incipiente" (FERNANDES, 2010, p. 28)

A aproximação entre elementos expressivos eruditos e o universo popular se desenrola desde o século XIX como atividade de criação dos mediadores. Peter Burke (1989) atribui aos mediadores da Europa moderna, a exemplo dos escritores, advogados e frades o contato com a cultura popular decorrente das atividades que exerciam, da mesma maneira, os livretos populares e a literatura de folhetos faziam circular informação para uma parte população letrada de determinadas regiões. 
4 A grande tradição era transmitida formalmente nos liceus e universidades. Era uma tradição fechada, no sentido em que as pessoas que não freqüentavam essas instituições, que não eram abertas a todos, estavam excluídas. A pequena tradição, po outro lado, era transmitida informalmente. Estava abeta a todos, como a Igreja, a Estava abera a todos, cono a Igreja, taverna e a praça do mercado, ond ocorriam tantas (BURKE, 1989, p. 54-55).

${ }^{5}$ O termo Escola de Frankfurt designa o conjunto de intelectuais que fizeram parte do Instituto de Pesquisa Social, fundado em 1923 em Frankfurt, e que tem em comum proposta e o desenvolvimento de una teora proposta e o desenvolvimento de uma teori crítica das modernas sociedades capitalistas, que se desdobra em três eixos temáticos principais: 1) a dialética da razão iluminista e a crítica da ciência; 2) a dupla face da cultura e a discussão da indústria cultural; 3 ) a questão do Estado e suas formas de legitimação. Dentre seus representantes podemos destacar: Theodor Adomo podemos destacar: Theodor Adorno, Max Hor. Benjamin, Eric Fromm, entre outros.
Para o autor esses mediadores orientaram uma coexistência entre grande e a pequena tradição ${ }^{4}$, fato fundamental da vida cultural e para compreensão da relação entre as influencias exteriores à comunidade. Fernandes (2010), Reis (2003) argumentam que a orientação dos artistas e intelectuais em direção ao um estreitamento, seleção e elevação das formas e dos agentes populares com coisas nossas seria uma influência externa ao contexto brasileiro.

É possível pensar um campo de profissionais formados por compositores, cantores e musicistas populares já na década de 1930; esses, bem poucos, sobreviviam com a renda da sua arte, contudo, pessoas como Donga, Cartola, Jacob Bandolim retiravam a renda das suas sobrevivências de atividades externas ao mundo musical.

O samba apesar de sua desconfortável origem galgaria espaço de prestígio, pelo menos em relação ao choro, nas estruturas comerciais da música, sintetizado junto ao projeto de estado nacional. A consolidação de uma sociedade urbano industrial a partir da década de 1940 coincide com a constituição de uma cultura de massa: “A expansão da indústria, o processo crescente da urbanização, o alargamento da classe operária, aliados ao advento da burocracia que gerou novas formas de controle gerencial, o desenvolvimento do setor terciário" (ORTIZ, 2001, p. 39) impeliram a expansão dos meios de comunicação como o rádio. Este, agora, contava como nova tecnologia permitindo melhor irradiação das ondas sonoras para maior número de cidades.

A recepção das ideias sobre cultura de massa no Brasil é datada nos anos sessenta e teve como principal referência as concepções da chamada Escola de Frankfurt ${ }^{5}$. No que diz respeito à problemática da cultura de massa, os frankfurtianos inserem esse assunto na formulação da indústria cultural. O emprego desse termo foi utilizado para caracterizar a cultura produzida para o consumo de massa, por meio de um processo de mercantilização, tornando valor de troca os ideais de felicidade, humanidade e justiça. Nesse sentido, o produto cultural integrado à lógica do mercado e das relações de troca deixa de ser "cultura" para tornar-se valor de troca (FREITAG, 2004).

No caso brasileiro, a indústria cultural se consolida no momento em que as forças da modernidade já se encontram alicerçadas, e a questão do popular acomodada aos projetos "das elites artístico-culturais de sintonizar o país com o "relógio" da modernidade (FARIAS, 2000, p. 20)". A década de 1940 é marcada para Ortiz (2001) como o período de expansão dos centros produtores de bens culturais através do rádio, cinema, jornais e revistas. O aumento do número de leitores proporcionado por 
Ver conversa entre a cantora Marisa Monte e as pastoras da Velha Guarda de Portela no DVD Mistério do Samba (2008). políticas de alfabetização em massa, tendo como objetivo a redução do exorbitante número de analfabetos e encaminhar esse contingente populacional ao mercado de trabalho e ao consumo, como estratégia de fortalecimento do mercado interno, formam os fatores preponderantes para a expansão da cultura de massa.

A chegada da televisão nos anos de 1950 alavanca os empreendimentos culturais de cunho empresarial para o mercado. Não desconsideramos a ineficiente profundidade da modernização para um mercado de cultura na sociedade brasileira nesse momento, pois somente alguns setores foram diretamente atingidos com esses valores: "O reflexo dessa debilidade aparece no campo da profissionalização das atividades culturais que sofria com ausência de regulamentação agravada com a fraca penetração de sua produção na população” (ORTIZ, 2001, p. 45).

Segundo Renato Ortiz (2001), até a década de 1970 o mercado brasileiro de bens culturais era ainda incipiente, mas havia espaço para uma diversidade estética muito maior do que nas décadas seguintes. Por isso, foi possível nesta época o lançamento nacional de determinados grupos de "talentosos" com grande destaque nos meio de comunicação:

O mercado brasileiro sob a égide da expansão ao progressivo aumento do consumo de disco que passa de 25 milhões em 1972 para 64 milhões em 1979, o multinacionais aqui para a diversificação dos lançamentos (p. 128).

De fato, foi também nesta época que diversos sambistas conquistaram espaços privilegiados no mercado de música. A procedência era variada; os festivais com no caso de sambistas como Beth Carvalho, Paulinho da Viola e Martinho da Vila se tornaram artistas nacionais gozando de ótimo prestígio junto aos meios de comunicação e com excelentes vendagens de discos; outros com os lendários fundadores das escolas de samba que já atuavam em rodas e casas noturnas, tais como Cartola, Zé Ketti, Nelson Cavaquinho, a Velha Guarda de Portela, Dona Ivone Lara, Wilson Moreira, Nei Lopes, entre muitos outros com Clara Nunes e Alcione que conseguem posição junto a esse time representando o samba na indústria fonográfica (NAPOLITANO, 2005; TROTTA, 2006).

As mulheres compositoras de samba foram apresentadas ao público a partir da década de 1970, com as pioneiras, Dona Ivone Lara e Leci Brandão. Em épocas anteriores residia o discurso que o fazer samba não era coisa para mulher, a posição ocupada por elas era o da cozinha. ${ }^{6}$

O samba como as demais expressões artísticas ao se modernizar, aqui nos referimos à adesão, à sistematização do 
mercado, a racionalização empresarial, às inovações tecnológicas e ao carreirismo profissional, confere aos segmentos masculinos lugar de reconhecimento e prestígio. Persiste o residual de naturalização da diferença entre os sexos, nos anos 1940, ou sobre a inferioridade das mulheres aplicadas ao domínio da criação musical, produzindo um imaginário "segundo as quais as mulheres seriam desprovidas de gênio, no sentido de uma aptidão inata e de uma disposição natural" (CARVALHO, 2010). Estariam ausentes nas mulheres os dispositivos orientadores para as coisas do "espírito", portanto, os aparelhos educacionais cumpriam a função de não cultivar o espírito suprimindo e/ou reduzindo conteúdos que ativassem a criação feminina.

No mundo do samba, com especial atenção às mulheres vinculadas a ele, provenientes dos grupos negro-mestiços, elas são localizadas no exercício da dimensão do cuidado. A prática do cuidado expandido para todas as dimensões da sociabilidade humana determina, o gênero feminino, vetor principal deste exercício. Quando essa concepção se agrega ao reduzido capital simbólico expresso na conjugação de variáveis como renda, escolaridade, cor/raça, confere desvantagens em relação aos outros estratos melhor situados na pirâmide social. Uma das chaves explicativas para compreender a posição secundária das mulheres compositoras, no universo do samba, são os reflexos do sistema no qual as estruturas são incorporadas nos indivíduos por uma rede de interações de uns com os outros.

Participar do campo musical requer tomar posse das regras e disposições que aí são mobilizados em forma de habitus, princípios que orientam a posição dos seus agentes aí inscritos. Portanto, a tímida existência das compositoras no campo da produção musical está diretamente relacionada com as estruturas objetivas que se organizam através dos determinantes de classe, gênero, geração e raça/cor apresentadas e incorporadas às estruturas subjetivas que no exercício não consciente reproduzem as exclusões ao se autoexcluírem.

O samba de autoria feminina no amplo espectro do que se convencionou classificar de música popular brasileira ganha espaço a partir da década 1970. A partir desse momento, e nos anos seguintes, as mulheres compositoras ganharam maior autonomia representando para elas a possibilidade de trabalhar e criar a sua independência financeira.

Tomando por base o texto "A dominação simbólica" para fazer a leitura sobre a posição da produção das compositoras e sua inserção no campo do samba, compreendemos que esse espaço de disposições (habitus) produzidas e reproduzidas, afeta tanto os 
homens como as mulheres, em particular todas as atividades técnicorituais, as quais são fundamentadas as estruturas do mercado de bens simbólicos. De acordo com Bourdieu (1996), em quase todas as sociedades, de todos os tempos, o homem depositou sua autoridade sobre as mulheres. Por meio da opressão, eles conquistaram o direito, culturalmente legitimado de exercerem a violência simbólica tanto nos espaços privados quanto nos públicos. A permanência dessa opressão se explica pelo fato de muitas mulheres se tornarem depositárias dessa exclusão.

Porém, em cada momento histórico podemos inventariar esquemas de representação das mulheres por meio da cultura e das artes, afirmando de diferentes modos a inferioridade de tudo que está relacionado com o feminino, mas, sobretudo, os modos como as mulheres conseguiram criar estratégias e instrumentos para transitar nas lacunas dos possíveis.

As motivações e as formas como essas mulheres conseguiram construir seu "nome" como compositoras estão articuladas com os novos arranjos que se impõem sobre elas, e sobre os espaços que ainda permaneciam restritos as suas participações. Com novos arranjos, queremos nomear todas as inovações decorrentes da modernização brasileira, em todas as suas dimensões, política, econômica e cultural, para assim olhar através da lente do samba as permanências da condição feminina historicamente situada como ligadas às coisas do doméstico.

O desempenho dos papéis de tias, pastoras e preparadoras da comida direcionados às mulheres foram subvertidos ao longo do tempo, propulsionados por fatores como: aumento de acesso ao ensino em todas as modalidades, expansão do mercado de trabalho feminino, participação na esfera pública, distanciamento das tarefas domésticas e da reprodução e redução da família devido o uso de contra contraceptivos e retardamento do casamento.

Mesmo que esses fatores possam ser empiricamente observados com mais acuidade nos setores mais favorecidos, eles chegam a todos os agrupamentos sociais através da circulação desses novos comportamentos por meio das redes de sociabilidade.

Portanto, a produção da composição de autoria feminina se insere no campo musical a partir das possibilidades de objetivação da sua obra. As movimentações históricas, econômicas e simbólicas no sentido de adesão aos novos agentes imprimem o aparecimento da singularidade, tendo em vista, as disposições previstas e as posições requeridas para a constituição do reconhecimento do músico. 


\section{O pioneirismo de D. Ivone Lara}

7 Grêmio Recreativo Escola de Samba (G.R.E.S) Império Serrano.

${ }^{8}$ Aniceto, Mano Décio da Viola e Silas de Oliveira, juntamente com Antônio do Santos, (Mestre Fuleiro), Sebastião de Oliveira (Molequinho) e Tio Hélio são os fundadores da Escola de Samba Império Serrano em 1947. Aniceto dividia sua atividades do samba com as de estivadore o Porto do Rio de Janeiro, ganha o cargo te Porto do Rio de Janeiro, ganha o cargo e orador da escola de samba Império Serrano a e consagrou-se como grande partideiro imbatível e reconhecido como ta o. D. Ivone Lara sobre declarava sobre ele: quem ouve Aniceto cantar um partido alto, não esquece sua raiz. "É nosso professor, para mim ele é um parente".
Podemos comparar D. Ivone Lara à Chiquinha Gonzaga dos anos 1940, porque, como Chiquinha, também transitava entre dois mundos. Explico-me, Ivone nasce numa família pobre, cuja tradição musical pertencia ao universo do carnaval e do samba, mas como fora aluna do internato por mais de dez anos, a aproximação com a música erudita se deu durante o período em que estudou num internato, local de aprendizagem de teoria musical com a esposa de Heitor Villa-Lobos, Lucília Villa-Lobos. Ao mesmo tempo, a sua família era composta de sambistas, participantes de festividades e rodas de samba; logo, a sua casa era um reduto do mundo popular.

Foi no final da década de 1940, quando as alas de compositores das escolas de samba eram exclusivamente masculinas, que "ela tornou-se a primeira mulher a integrar - com o mesmo poder decisório dos homens - uma ala de compositores de sambas-enredo, da verde-e-branco de Madureira ${ }^{7 "}$ (BURNS, 2006, p. 69), momento de início de sua carreira artística, que ainda era dividida com as tarefas domésticas e com o trabalho de assistente social. Aposentada em 1977, somente aos 56 anos D. Ivone Lara começa a se dedicar integralmente ao seu papel de compositora. D. Ivone Lara pertence à geração de sambista que girava em torno da
Escola Império, no bairro de Madureira, representada por Aniceto Menezes e Silva Jr.(1912-1993), Mano Décio da Viola (1909-1984) e Silas de Oliveira (1916-1972), que passariam serem mais tarde seus parceiros em algumas composições. ${ }^{8}$

Pertencente a uma geração de sambistas e compositores negromestiços dos anos 1940, moradores dos subúrbios cariocas, empobrecidos, situado em postos de trabalho braçal, a exemplo do próprio Aniceto, que era estivador no cais do porto do Rio de Janeiro, D. Ivone Lara afirmou à pesquisadora Burns (2006) que o fato de ser mulher e negra se constituiu em uma das barreiras enfrentadas para o início de sua carreira.

No entanto, D. Ivone nos relembra de uma criação desenvolvida durante a sua fase juvenil:

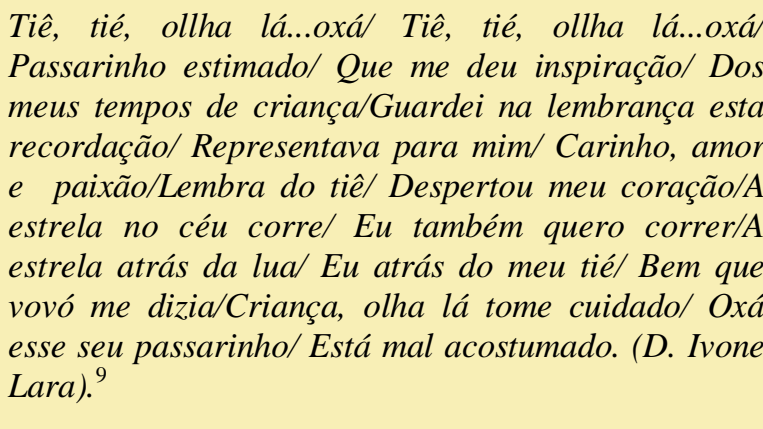

Para a baluarte do samba carioca, autora de melodia da música Tiê-tiê, feita quando ela tinha doze anos, a sua carreira tardia sofre 
${ }^{9}$ Primeiro samba de partido alto de autoria de D. Ivone Lara e, segundo www.dicionariompb.com.br, escrito aos 12 anos.

${ }^{10}$ Em 2011 quando fez 90 anos de idade, dentre os eventos comemorativos, foi lançado

www.donaivonelara.com.br, projeto que contou com apoio financeiro da Secretaria de Estado de Cultura do Rio de Janeiro. com o favorecimento da ausência de outras compositoras de samba no mesmo período, década de 1970 . Momento este do lançamento do long play "Samba Minha Verdade" e "Samba, minha raiz", do encontro com a compositora Rosinha de Valença e com a intérprete baiana Maria Betânia que gravará o conhecidíssimo "Sonho Meu", samba que rende a D. Ivone Lara o reconhecimento do público carioca $^{10}$

Desde daí vem seguindo gravando e compondo com o seu mais recente parceiro Bruno Castro. Possui uma geração de herdeiras como Lecy Brandão e, mais recentemente, Telma Tavares, Ana Costa, Martinália, Nilze Carvalho e Teresa Cristina, dentre outras.

\section{A guerreira Leci Brandão}

Lelelelê Lelelelelelelelelê /Lelelelê Lelelelelelelelelê /No serviço de alto-falante /Do morro do Pau da Bandeira /Quem avisa é o Zé do Caroço /Que amanhã vai fazer alvoroço /Alertando a favela inteira /Como eu queria que fosse em Mangueira /Que existisse outro Zé do Caroço (Caroço, Caroço)/Pra dizer de uma vez pra esse moço/

Carnaval não é esse colosso /Nossa escola é raiz, é madeira /Mas é o Morro do Pau da Bandeira /De uma Vila Isabel verdadeira /O Zé do Caroço trabalha IO Zé do Caroço batalha /E que malha o preço da feira/E na hora que a televisão brasileira /Distrai toda gente com a sua novela /É que o Zé põe a boca no mundo /Ele faz um discurso profundo/Ele quer ver morro do Pau da Bandeira /Esta nascendo umo novo morro do Pau da Bandeira Lsta nascendo um novo líder No morro do Peir da Bandeira No morro do Pau da Bandeira/No morro do Pau da Bandeira.(Zé do Caroço. Composição de Leci Brandão).

Filha única de um funcionário público e de uma servente, Leci Brandão cresceu nutrindo a consciência de suas origens sociais e familiares. É em casa, no ambiente familiar e na convivência cotidiana que a sambista recebeu as primeiras referências musicais; através do gosto musical do pai entra em contato com músicos nacionais como Jamelão, Carmen Costa, Jacob do Bandolim, Elizeth Cardoso, Doris Day, Louis Amstrong, dentre outros. Além de nutrirse de referências musicais negras e internacionais, o gosto musical de Leci Brandão também se direcionava para os ecos da música produzida em solo nacional. As inovações estéticas da bossa nova, o frenesi da Jovem Guarda e as músicas de protesto frente á ditadura militar, modelaram sua primeira composição de 1964, intitulada “Tema de amor de você” (PEREIRA, 2010, p. 23).

Como aluna do curso de Direito na Universidade Gama Filho participa do I Festival de Música dessa universidade em 1970. Apresentou o samba "Cadê Mariza", obtendo o $2^{\circ}$ lugar sendo gravado no seu primeiro disco em 1975. Segundo Pereira (2010), a letra dessa canção sinaliza as predileções poéticas da artista que, no 
${ }^{11}$ O Opinião foi um espetáculo criado por Oduvaldo Vianna Filho, Armando Costa e Paulo Pontes, com direção de Augusto Boal, que entre 1964 e 1975 constituiu-se como foco de resistência ao regime militar. (Cf. PEREIRA, 2010, p. 31)

${ }^{12}$ Recebe a denominação hoje de Prêmio Tim que, desde 1987, premia a música popular brasileira nas suas várias vertentes. decorrer da carreira, buscou contar em seu canto histórias e cotidiano de gente simples e anônima. A artista também se aproxima de alguns fundamentos da canção engajada.

Em 1972 é aceita à Ala de Compositores do Grêmio Recreativo Estação Primeira de Mangueira, mobilizando um deslocamento no campo de ordem geracional, gênero e racial ao ser a primeira mulher a ingressar nesse famoso reduto masculino por agregar nomes já consagrados como os de Cartola, Nélson Cavaquinho, Nélson Sargento e Carlos Cachaça. A partir de então, se dedica integralmente ao samba participando das iniciativas da I e II Bienal do Samba, nas edições em que acontecem entre 1968-1971, espaço para o fomento e reverência ao gênero na música popular. A proposta das bienais era possibilitar a alguns representantes da velha geração do samba, afastada da mídia e da indústria cultural musical à época, colocar-se diante de um novo público através da mídia televisiva como foi o caso de Ismael Silva, Donga, Ataulfo Alves, Adorinan Barbosa

A participação na ala dos compositores da Mangueira, cujo posicionamento geográfico próximo à zona sul, área nobre da cidade, em relação às outras agremiações, ao lado da articulação com os segmentos sociais hegemônicos da sociedade carioca, permitiu a Leci Brandão maior visibilidade e contato com os produtores culturais como, por exemplo, Sergio Cabral. Nessa época, além dos sambas românticos, já produzia também alguns com letra politizada como, por exemplo, "Deixa pra Lá”, que chamou atenção do grupo ligado ao show Opinião ${ }^{11}$. Este foi parte de uma série de shows apresentados na mesma zona sul com e mesmo nome, retratando a visão de parte da classe média identificada com os princípios da esquerda política de então, que tinham na figura do “povo", na valorização e na educação deste, um dos seus meios para a transformação social.

O ano de 1973 marcou o início efetivo da profissionalização de Leci Brandão, com o convite feito pelo jornalista Sérgio Cabral para integrar justamente o elenco fixo dos shows no Teatro Opinião. Em 1989, ela participou do Festival MPB-Shell promovido pela Rede Globo, conseguindo levar sua composição Essa tal criatura à finalissíma do evento, realizada no Ginásio do Maracananzinho. Nos anos 1990, Leci já reunia nove discos gravados, dois prêmios Sharp ${ }^{12}$, um disco de ouro e uma carreira que se solidificava a partir da opção e maturidade da artista em fazer da música seu principal veiculo de expressão na televisão e no rádio, onde atuou em programas ligados ao samba e ao carnaval no Rio de Janeiro e São Paulo. 
Para além dos discos e dos shows, Leci Brandão construiu uma imagem de cantora politizada, por se vincular as temáticas de interesse da população negra, não possuía até 2010 nenhuma filiação partidária e nem inserção nos movimentos negros. Sua militância tem se expressado na defesa do samba e das agremiações do samba como patrimônio da comunidade, em oposição aos diferentes aspectos da modernização das escolas que resultaram especialmente na exclusão de seus antigos integrantes em favor de novos personagens, mulheres e homens das classes sociais mais abastadas. (WERNECK, 2007)

\section{Considerações finais}

Pouco ainda se fala da mulher compositora no universo da música. Esse espaço como ficou constatado na nossa pesquisa ainda pertence aos homens, sendo a elas relegadas no mundo do samba a interpretação, "tias", "pastoras", responsáveis pela comida e organização da festa. Estão imersas nos papéis secundarizados, porque a composição é o espaço do poder

Espaço da afirmação da autoria na esfera pública, onde a dominação masculina se inscreve nas estruturas cognitivas e corporais tanto de homes e mulheres que inconscientemente reproduzem a opressão. Durante a realização de nossa pesquisa constatamos que D. Ivone Lara e Leci Brandão construíram um legado ao se tornarem referências para as novas gerações de compositoras.

Tornaram-se, assim, mobilizadoras de renovações estéticas do estilo musical em questão, o samba, assim como através dos seus itinerários deslocaram preconceitos e hierarquizações profissionais. Contribuíram, cada uma no seu tempo, para a elevação do samba como gênero musical e, ao mesmo tempo, suas conquistas foram potencializadas em direção da abertura de novos caminhos para trabalhos autorais de outras mulheres.

\section{Referências Bibliográficas}

ABREU, M. Da habitação ao habitat: a questão da habitação popular no Rio de Janeiro e sua evolução. Revista Rio de Janeiro, $\mathrm{n}^{\circ} 10$, mai-ago, 2003.

BOURDIEU, P. A ilusão biográfica. In: Razões Práticas. Campinas: Editora Papirus, 1996

BOURDIEU, P. As Regras da Arte: gênese e estrutura do campo literário. $2^{a}$ ed. São Paulo: Companhia das Letras, 1996.

BURKE, P. (1989). Cultura popular na idade moderna. São Paulo: Companhia das Letras, 1989. 
BURNS, M. (2007). A dona da voz e a voz da dona: a trajetória de Dona Ivone Lara. In: VELHO, G. (Org.). Rio de Janeiro: cultura, política e conflito. Rio de Janeiro: Jorge Zahar, 2007.

CARVALHO, D. V. de. Renome, vocação e gênero: duas musicistas brasileiras. Dissertação (Mestrado em Antropologia), Universidade de São Paulo, 2010.

FARIAS, E. Ócio e Negócio: festas populares e entretenimentoturismo no Brasil. Tese (Doutorado em Ciências Sociais), Universidade Estadual de Campinas, 2000.

FENERICK, J. A. Nem do morro, nem da cidade: as transformações do samba e indústria cultural. 1920-1945. Tese (Doutorado em História), Universidade de São Paulo, 2002.

FERNANDES, D. C. A Cor do Samba. Anais do XIV Congresso Brasileiro de Sociologia. Rio de Janeiro, 2009.

FERNANDES, D. C. A inteligência da música popular: a "autenticidade" no samba e no choro. Tese (Doutorado em Sociologia), Universidade de São Paulo, 2010

FREITAG, B. Teoria Crítica ontem e hoje. São Paulo: Brasiliense, 2004.

LIMA, E. T. Um olhar sobre o Teatro Experimental do Negro e do Bando de Teatro Olodum. Tese (Doutorado em Artes), Universidade Estadual de Campinas, 2010.

LIPPI, L. Cultura urbana no Rio de Janeiro. In: Ferreira, M. M. (Org.). Rio de Janeiro: uma cidade na história. Rio de Janeiro: Ed. Fundação Getulio Vargas, 2000.
NAPOLITANO, M. História \& Música: história cultural da música popular. $3^{\mathrm{a}}$ ed. Belo Horizonte: Autêntica, 2005.

ORTIZ, Renato. A moderna tradição brasileira. São Paulo: Brasiliense, 2001

PEREIRA, C. dos S. Coisas do meu pessoal: samba e enredos de raça e gênero na trajetória de Leci Brandão. Dissertação (Mestrado em História), Universidade de Brasília, 2010.

REIS, L. V. S. (2003). “O que o rei não viu”: música popular e nacionalidade no Rio de Janeiro da Primeira República. Estudos Afro-asiáticos. Ano 25, no 2, 2003.

SANDRONI, C. Feitiço decente: transformações do samba no Rio de Janeiro (1917-1930). Rio de Janeiro: Jorge Zahar; Ed. UFRJ, 2001.

TINHORÃO, J. R. História Social da música popular brasileira. São Paulo: Ed. 34, 1998.

TROTTA, F. C. O samba e o mercado de música nos anos 1990. Tese (Doutorado em Comunicação), Universidade Federal do Rio de Janeiro, 2006

WERNECK, J. P. O samba das ialodês: mulheres negras e a cultura midiática. Tese (Doutorado em Comunicação), Universidade Federal do Rio de Janeiro, 2007. 